\title{
Intelligence and its Application in Agriculture: Techniques to Deal with Variations and Uncertainties
}

\author{
Kaushik Bhagawati*, Rupankar Bhagawati and Doni Jini \\ ICAR Research Complex for NEH Region, Arunachal Pradesh Centre, Basar-791101, India \\ *E-mail: kaushik.iasri@gmail.com
}

\begin{abstract}
Biological systems, including agriculture and allied sectors are very complex and nonlinear in nature. The pace of current climate change, which is unique about it, makes the biological system more and more complicated and unpredictable. The novelty or ambiguity that the variable environment presents, demands for the development of self-adaptive intelligent systems in agriculture and allied sectors. Agriculture is emerging as knowledge-based enterprise that demands efficient needbased information retrieval systems and smart actions. Intelligence is that resource that guides actions and provide options under variable, uncertain and unseen conditions. The objective of the current paper is to analyze the attributes that are considered to be characteristics of intelligence having wide potential for the development of intelligent system and technologies for agricultural applications. The intelligent techniques like forecasting, database management, knowledge discovery, deception, simulation, contingency planning etc. revolutionize the whole agricultural sector opening new and competent options and dimensions. Sustainable agricultural development demands multidisciplinary holistic approach and intelligence should be the guiding principle that demands study of human cognitive psychology.
\end{abstract}

Index Terms-Intelligence, cognitive, agriculture, climate change, sustainability.

\section{INTRODUCTION}

Intelligence is the least understood concept till date. Based on our current understanding, intelligence may be defined as the analyzing power of an entity based on the given set of information under the given situation. It is the ability of an entity or a system to learn from a given set of conditions, store the knowledge in a well defined hierarchical manner and apply that knowledge in situation-specific manner in a very logical way. In general an intelligent system can learn, store the learned information and use it in varying situation [1]. Learning is the ability to get knowledge from experience or when being taught. Also, learning change approach of doing certain things, gradually and finally made the entity to behave in a smart way. Information is the basic means or tool to learn or to teach a system or an entity. The acquired information associated with certain subject or object is knowledge. And the process of extracting information relevant to a given context from a pile of raw data is knowledge discovery. Thus, the ability of a system to discover knowledge from available data and use it for some future unseen and new situations is under the domain of intelligence [2] and its application is emerging in every sphere of science and technology. Currently lot of functional or practical significance and emphasis is being given to intelligence because of the ability of an intelligent system to deal with complex or adverse or variable situations.

Agriculture depends on the decision making, with right decision at right time. Even a marginal difference may yield big gain or losses over time. Change is inevitable process in nature and the change brought by nature is always been a gradual and slow process giving ample time and space for each entity to adapt and change themselves as per the external change. But the unprecedented pace of current climate change gives no time for each entity to adapt as per the change and lead to unbalance in every aspect. Agricultural system needs to be intelligent and self-adaptive to make it sustainable and resilient to ongoing changes in climate and social structure. Agriculture is enterprising, and consequently depends on information for optimum resource use and management. For any enterprise, apart from the four factors of production viz. LAND, LABOR, CAPITAL and ENTREPRENEURIAL ABILITY, INFORMATION emerges as fifth vital factor [3]. Agricultural system in particular and biological system in general is a complex system that depends on multitudes of biotic and abiotic factors. Moreover, these factors in turn depend on several other factors. Thus, to study such system it is necessary to consider simultaneously several interrelated factors that cannot be dealt with normal mathematical or statistical methods. This lead to the introduction of intelligence and intelligent system in agriculture those are capable of dealing with such non-linear problems. The curving for intelligence in agriculture and allied activities has been there since its inception, because agriculture is fundamental of human civilization. But the latest IT and related technologies revolutionized agriculture and offer it a novel outlook. New approaches like Artificial Intelligence, Artificial Neural Network, Fuzzy Logic, etc. 
find wide application in agriculture and allied sectors. These are information processing system models that are built from human thought process to mimic human brain's decision making abilities [4]. In fact they are part of the natural functioning of the human cognitive process. There has been behavioral change in agriculture. Firstly agriculture become 'Smart' by acquiring the behavior like predictive ability, quick learning, decision making etc., and secondly, it acquire those behavior that are associated with "Street smarts" like localized knowledge or know-how. How a system performs certain task or job is the measure of the general ability of an intelligent system. Research from cognitive psychology has increased understanding of the nature of competent performance and the principle of knowledge organization that underlie people's abilities to solve problems under wide variability and uncertainties. The current paper briefly enumerates some attributes of intelligence that find extensive application in agriculture and allied sectors. The objective of current study was to understand intelligence as such and its potential application in agricultural systems.

\section{AtTRIBUtes OF INTELLIGENCE}

Attributes of intelligence are those factors that can make a system to behave intelligently. There is no sharp boundary that differentiate between these attributes, they are overlapping and fused on one another. Though the concept of human intelligence is still a mystery, but following attributes may be regarded as the characteristic of intelligence.

\section{A. Prediction}

Prediction is the most important aspect of intelligence. Prediction is defined as the statements about the way the things will happen in the future, often but not always based on our experiences [5]. The capacity to remember and predict patterns in the world, including language, mathematics, physical properties of objects, and social situations, is considered as intelligence [6]. No two events in this universe is exactly similar, the specific behavior, action and reaction is preceded by and depends on prediction. Biological neural system (especially human brain) receives patterns from the outside world; store them as memories, and makes predictions by combining past with the present. Predictions are made by combining the invariant or stored memory recall of what should happen next with the details pertaining to this moment of time. Thus prediction is made by analogy. Forecasting is mechanical or artificial way of prediction, focusing on the range of possible outcomes. Forecasting may be defined as the process of making prediction of the future based on past and present data and analysis of trends [7].

Whole science and scientific research are in fact predictions. Theories, hypothesis, assumptions, analysis are all predictions. The science of mathematics and statistics are particularly based on prediction. Prediction, especially forecasting, has wide application in biological system, owing to variability and uncertainties in the system. Advance information of weather, disease incidences, crop yield etc. are some of the most common application of intelligence in agriculture and has lot of significance. In basic term, such information helps the farmers and other stake holders in decision making and to take proper precautionary and preventive measures at appropriate time to avoid or lower the effects, leading to judicial use of resources. Forecasting using natural indicators and phenomenon is integral part of indigenous traditional communities $[8,9]$. Forecasting evolved with time into a specialized branch of statistics and mathematics. There is multitude of statistical and numerical forecasting techniques; weather, crop yield and disease forecasting being vital for agricultural and allied sectors. One of the most important forecasting techniques is Artificial Neural Network (ANN) that is extensively used in agriculture and allied fields [10,11,12]. Unlike the traditional model-based techniques, ANNs are datadriven self-adaptive method that learns from examples [13]. ANN can often correctly infer the unseen part of the population. ANNs are originally developed to mimic the human biological neural systems. The general ANN model with Feed Forward Multilayer Perceptron Architecture is depicted in the Fig. 1. Another method that is becoming popular among the researchers is Support Vector Machine (SVM) for forecasting [14]. The weather forecasting techniques like General Circulation Model, Numerical Weather Prediction etc are all about prediction and forecasting.

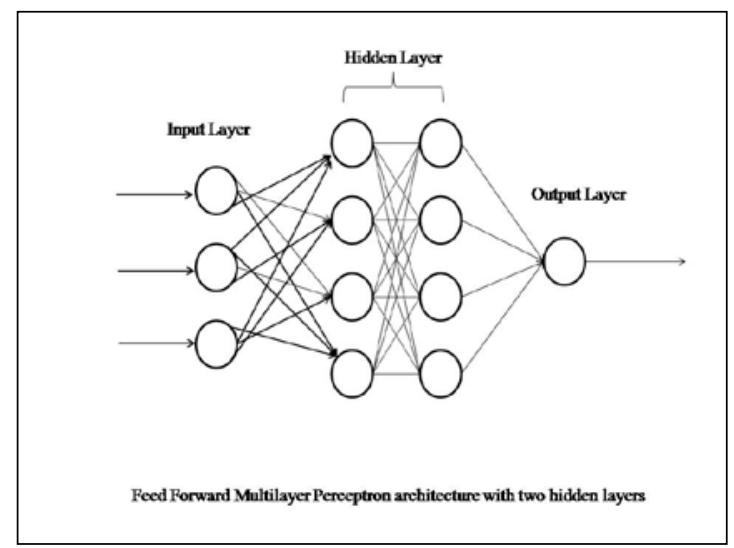

Fig.1. Feed Forward Multilayer Perceptron Architecture with two hidden layers

\section{B. Stored Memory}

One of the important aspects of the human brain is ability to store information and to memorize. Though no definite agreed upon mechanism how brain stores information is yet reached, but brain do stores information. This is one of the very fundamental attribute of intelligence. Not only it stores information, but retrieve it as per the need and situation. In fact, human brain solves and analyzes information using stored memory [6]. When human brain is exposed to some situation, it does not go for all analytical steps to react, rather it compare it with past memories and act 
accordingly. If the situation is very novel, it act by prediction and store the experience in the memory (which is, infact, learning). Thus, a similar or near similar event is not a matter of interest for brain. But a fresh event or incidence or situation or circumstances causes stress because of brain's effort to correlate it with previous such incidences or its effort in finding possibilities and in prediction. Thus, either prediction is made about the outcome of an event followed by action as per prediction and storage of the phenomenon (Prediction-ActionStorage), or brain correlate the event with the similar past events and act accordingly followed by storage in memory (Correlation-Action-Storage). The stored memories in turn furnish future predictions and make them more precise.

This attribute of intelligence is very widely used almost in every scientific domains including agriculture. Each and every small or big enterprise, organizations and institutions have their dedicated databases and database management system for data storage and efficient information retrieval mechanisms. Every agricultural information systems, decision support systems, forecasting systems etc. have efficient database behind them that ensures timely, secure, reliable and prompt data delivery and storage. These massive databases coevolving with new research methodologies in agriculture with widespread application of information technology could be a precious repository of information for the decision makers, right from researchers to the farmers. The prominent agricultural databases includes AGRIS (International Information System for the Agricultural Sciences and Technology), FAOSTAT [15], AQUASTAT (Global Information System for Water and Agriculture) [16], CountrySTAT [17], GIEWS (Global Information and Early Warning System) [18], GLiPHA (Global Livestock Production and Health Atlas) [19] etc of Food and Agricultural Organization of the United States. Other important agriculture related databases are AGRICOLA, CAB Direct, CARIS (Current Agricultural Research Information System), Scopus, etc. These are one aspect of memory called the declarative memory i.e. one that can be expressed verbally. But there is another aspect of human memory that cannot be explained verbally [6]. For example, if someone is asked how to balance a bicycle, he may provide advice to hold the handles and push the pedals, but cannot explain how to do it. This aspect of memory, that which is called 'consciousness' need to be studied for developing intelligent databases.

\section{Ability to learn}

The ability to learn from the experiences and external inputs is another very important attribute of intelligence. Learning is defined as "to gain knowledge or skill from experience, by studying and from being taught" [20]. Experience gain through exposure to new situation or happening is learning. Learning is an incremental process; with more exposure varied situations results in more learning. What is learned is stored in a well structured hierarchy of memories. This stored learning is our knowledge. When similar condition or situation arises, they can be dealt in the best possible way through our knowledge of past incidences. Ability to learn is thus an important step in prediction. Learning is thus a knowledge discovery process from the multitude of events happening continuously. Active learning increases skill and versatility of an entity.

The widespread use of computers and affordable storage facilities lead to the generation of gigabytes and terabytes of data that are piling up in the databases of different organizations, institutions and companies. The advent of internet and associated World Wide Web further multiply the accessibility of data thousand times. Thus, the demand for intelligent technology and techniques arise to derive information from these data sets. The major challenge is to infer valuable information from the observed data that may have unexplored potential to improve the efficiency of the related sector, which lead to the emergence of techniques of Data Mining that find wide application in agriculture and allied sectors. The major focus and intension of the technique is to use existing data to invent new facts and to uncover new relationships previously unknown even to the experts [21]. In Agriculture, Data Mining techniques have been recently used for recognizing and grading fruits [22]. In China, the relation between climate change, water resources and agriculture was undertaken using the technique of Data Mining [23]. Data mining is recognized as the most advance concept for prediction of market fluctuation and price variability. Ding et al, (2010) [24] used the technique of Decision Tree for prediction of market price of pig in China. Techniques of Data Mining like Fuzzy set and interpolation techniques are applied for land suitability evaluation for maize in Northern Ghana [25]. The major Data Mining techniques are shown in table 1.

Table 1. Data Mining Techniques

\begin{tabular}{|c|c|c|}
\hline Sl. No. & Subject & Techniques \\
\hline 1. & Statistics & $\begin{array}{l}\text { Correlation analysis, Cluster } \\
\text { analysis, Factor analysis, Linear } \\
\text { Discriminants, Quadratic } \\
\text { discriminants, K-nearest Neighbor, } \\
\text { Logistic Regression, CART, etc. }\end{array}$ \\
\hline 2. & $\begin{array}{l}\text { Machine } \\
\text { learning }\end{array}$ & $\begin{array}{l}\text { Neural Networks, Genetic } \\
\text { Algorithms, Support } \text { Vector } \\
\text { Machines, Decision Tree, Induction, } \\
\text { etc. }\end{array}$ \\
\hline 3. & Fuzzy Logic & $\begin{array}{l}\text { Exact Reasoning, Approximate } \\
\text { Reasoning, etc. }\end{array}$ \\
\hline 4. & $\begin{array}{l}\text { Rough Sets } \\
\text { Techniques }\end{array}$ & Decision Rule, Data Filtration, etc. \\
\hline
\end{tabular}

Research and development is now focusing on making a system to learn and act accordingly in a situationspecific manner. Learning from the previous incidences was given outmost significance in the recent time. Lot of learning algorithms were developed to teach the system. The most prominent being the back propagation algorithm [26,27] used in Artificial Neural Network that 
is used in several forecasting and forewarning system in agriculture [12, 28].

\section{Recognition}

A little child can distinguish a cat from a dog. But with millions of codes, thousands of electronic valves and hundreds of algorithms, the computer fail to differentiate a cat from a dog if it is slightly deformed. This flexibility of human mind to recognize is another noteworthy attribute of intelligence. Recognition can be defined as the act of remembering something or some phenomenon through senses, i.e. by seeing, hearing, touching and smelling. For a human mind, the whole picture of the entity is not required to recognize it; based on certain minimum attributes it can be recognized. An apple can be recognized either through its smell or shape or color or taste, etc.

Developing system that can recognize is in forefront of modern scientific research. The Neural Network technology is used widely in classification and recognition in several applications like speech recognition, mine detection, detection of chromosomal abnormalities, robotics and computer vision etc. The whole remote sensing technology is based on recognition and identification using techniques like spatial signature, false color combination, etc. Multitudes of sensors were developed for different applications.

ANN finds significant application in image recognition and classification of crops and yields [29]. In classification of plotted plants using ANN, an accuracy of 95 per cent was observed when apples are graded based on color [30]. In classification of wheat karnels by color, Wang et al (1999) [31] found accuracy of above 98 per cent.

\section{E. Deception}

Deception may be defined as the acts to propagate beliefs of things that are not true, or not entirely true. It involves pretending as something else away from its true character. Deception is an intrinsic part of all life; it aids in survival. It uses the constraints of the biological sensors or processors that are programmed to 'expect the expected' and thus can be deceived and can be fooled by illusion [32]. It is one of the intelligent responses of biological entity. Beside human being, deception is seen in almost in all living organism right from tiny amoeba to higher mammals, though used as adaptation strategies in the latter case. Plants also exhibit deception, the most common being the colorful flowers that attracts insects which in turn help them in pollination. The carnivorous plants like Nepenthaceace, Triphyophyllum, Sundews etc are significant indicator of deceptive character of plants. However, in animals and plants the deception is the part of their survival [33]. Deception like distraction, camouflage and concealment are being used as biological adaptation strategies.

Deception finds lot of positive application in agriculture and allied sectors. The most noteworthy example is the use of pheromone traps for monitoring and controlling the insects. The simple light trap and techniques like trap-crop are also examples of deception. Fig. 2 depicted the pheromone trap. This involves manipulation of the pest behavior for control of insects or pests [34]. Traps using sound or acoustics are also in use to monitor or control insects [35]. Poison treated food lures and baits are in use to control household pests since centuries [36]. The most remarkable thing about these techniques is their eco-friendly nature, as the end goals of these techniques are to change behavior of the entity involved. Current situation demands exploration and standardization of such techniques.

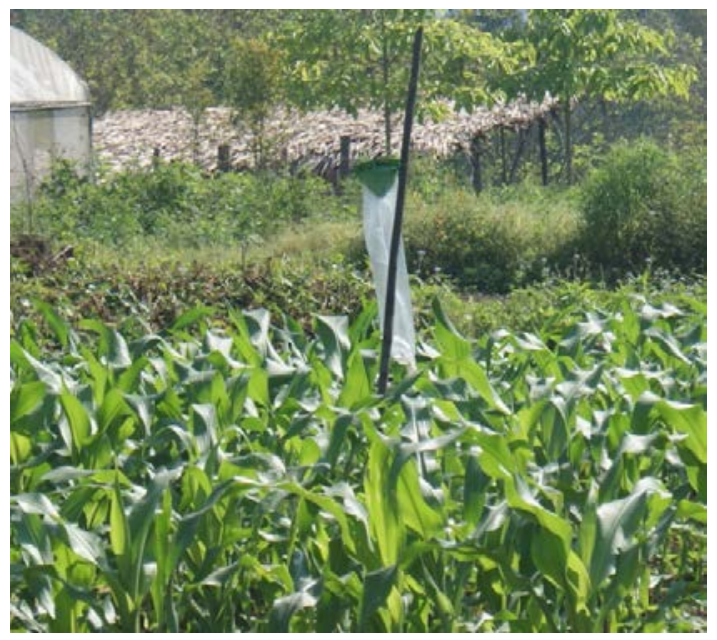

Fig.2. Pheromone trap used for monitoring and control of insects.

\section{F. Imagination}

Imagination is ability to create picture of something or visualize some event that does not exists. These are sensation in the mind that is not perceived through senses such as sight, hearing or other senses. Imagination helps make knowledge applicable in solving problems. Imagination is basic activity of human intelligence to have perception of something that does not happened or that may happen in future or that we expect to happen. Imagination enable to mentally rehearse something and to find possible remedies or strategies for possible outcomes, thus increases precision of reaction.

Generally imagination follows prediction. Once a situation is predicted, what will be the possible outcome or possible remedy out of the predicted situation is imagination. Imagination leads to innovation when an analogy is made with the past events or information. Planning is within the domain of imagination. Several models were developed to perceive the future possible events. The simulation models are one such model that can simulate the event that may possibly happen based on current and past information or experiences. By studying the large dataset, several simulation models have been developed viz. DSSAT [37], CROPSYST [38] and APSIM [39] to name a few to aid agricultural activities. The culture, education, customs etc teaches stereotypes that always results in biasness. So is the case with these models developed considering certain aspects of certain location and is mostly generalized. These models need to be tailored for the need of specific location, minimizing 
the stereotypes.

\section{G. Innovation}

Innovation is a new idea. It is ways of doing something in a new way. It is the new and unique approach towards the new requirements or need. It is something that is original. In practice innovation is that process that bring together various novel ideas in a way that change the outlook towards dealing with any issue. Innovation is one of the characteristic features of intelligence. Innovation may be non-linear i.e. its outcome may not be any combination of the previous experiences. Innovation or creativity is in fact prediction by analogy.

Some very common practice in agriculture is by definition an innovation. Contingency crop planning can be attributed to innovation. Based on the weather forecasting for the coming season, the cropping schedules, selection some set of varieties, employment of certain management practices, crop geometry etc were decided. This is innovation. Developing tailor made varieties for a particular location and for a particular situation is innovation. For example, with rise in global temperature, some temperate crops like apple is shifting towards higher altitudes due to requirement of high chilling hours [40], but this is compensated by introduction of low chilling requirement varieties like Anna, Dorset Golden, Tropical Beauty, Parlin's Beauty, Schlomit, Vered, Michal etc. Identification of farmers' indigenous local varieties and using it for developing better resilient varieties for the location is innovation. Any techniques or technologies tuned for a specific location based on its climatic and physiographic parameters of that location is innovation. So innovation finds wide application in agriculture. All indigenous traditional knowledge of doing something in a better way or to deal with some specific problems is innovation.

\section{CONCLUSION}

Variability of climate acts as a multiplier of uncertainties and complexities of agriculture and allied sector. The agricultural system need to adapt and behave according to the parallel change in environment and climate, i.e. the system need to be self-adaptive. This demands multidisciplinary holistic approach in a very sustainable way. Intelligence is one of the most important resources that need to be fused in the agricultural technologies. The advances in the research in human cognitive psychology need to be studied and need to be analyzed for their possible application in agriculture. Only intelligence can deal with variability and uncertainty. The systems so far developed are far behind the perceived concept of intelligence. They are good in calculation, fast in processing and gigantic in storage, but they cannot think and act as human brain. Taking advantage of the processing and storage speed of these technologies, systems can be built that can behave in a situation-specific manner aiding in better decision making and fast processing of the possible options. Thus, by understanding the biological and physical concept of intelligence, right information as per the situation can be retrieved and all actions can be tailored as per the perceived knowledge to smartly deal with the situation.

\section{ACKNOWLEDGMENT}

The authors acknowledge the support and help extended by all the scientific and technical staff of the research centre. We are especially thankful to Director of the Institute, Dr. S.V. Ngachan for his constant guidance and blessings. We are thankful to Dr. Anup Das for his cooperation and help.

\section{REFERENCES}

[1] L. S. Gottfredson. Practical Intelligence. In: FernandexBallesteros R (Eds.) Encyclopedia of psychological assessment. London: Sage, 200, pp: 740-745.

[2] R. L. Gregory. Knowledge in perception and illusion. Philosophical Transaction of Royal Society of London, 1997, vol.: 352, pp: 1121-1128.

[3] K. Bhagawati, P.K. Malhotra and R.N. Sahoo. GIS Assisted Farm Management Information System. Lap Lambert Academic Publishing, Germany,2012, pp-148.

[4] C.D. Wicken. Engineering Psychology and Human Performance ( $2^{\text {nd }}$ Edition). Harper Collins: New York, 1992.

[5] N. Cesa-Bianch and G. Lugosi. Prediction, Learning and Games. Cambridge University Press, Cambridge, UK, 2006. www.cambridge.org/9780521841085

[6] J. Hawkins and S. Blakeslee. On intelligence. Times Book. New York, 2005.

[7] J.S. Armstrong. Principles of Forecasting: A Handbook for Researchers and Practitioners (Section 8: "Neural Networks for Time-Series Forecasting”). Boston, MA: Kluwer Academic, 2001.

[8] V. Gupta. Community forest management - A case study of East Kameng district, Arunachal Pradesh, India, Consultancy report, CFMWG-NEI, NEHU, Shillong, India and Community Forestry International Inc., Santa Barbara, USA, 2004.

[9] T. Mugati and R.S. Maposa. Indigenous weather forecasting: A phenomenological study engaging the shone of Zimbabwe. The Journal of Pan African Studies, 2012, $9^{\text {th }}$ edition, vol: 49, pp: 102-111.

[10] C.C. Yang, S.O. Prasher, S. Sreekanth, N.K. Patni and L. Masse1997). An artificial neural network model for simulating pesticide concentrations in soil. Transactions of the ASAE 1997, vol.40, pp: 1285-94.

[11] Crisci, M. Moriondo and S. Orlandini. Analysis of downy and powdery mildew infection: modelling and neural network approach. In: Proceedings of the 7th ICCTA International Congress for Computer Technology in Agriculture, 1998. Florence, Italy.

[12] S. Chakraborty, R. Ghosh, M. Ghosh, C.D. Fernandes, M.J. Charchar and S. Kelemu. Weather-based prediction of anthracnose severity using artificial neural network models. Plant Pathology, 2004, vol. 53, pp: 375-386. Doi: 10.1111/j.1365-3059.2004.01044.x

[13] G. Zhang, B.E. Patuwo and M.Y. Hu (1998). Forecasting with artificial neural networks: A state of art. International Journal of Forecasting, 1998, vol. 14, pp: 35-62.

[14] R. Kaundal, A.S. Kapoor and G.P.S. Raghava. Machine learning techniques in disease forecasting: a case study on rice blast prediction. BMC Bioinformatics, 2006, vol. 7, 
pp: 485 doi:10.1186/1471-2105-7-48.

[15] FAO (2015a). www.faostat3.fao.org

[16] FAO (2015b). www.fao.org/nr/water /aquastat/

[17] FAO (2015c). www.fao.org/economic /ess/country/en/

[18] FAO (2015d). www.fao.org/giews/

[19] FAO (2015e). www.fao.org/glipha/

[20] J.A. Morgan and M.C. Fonseca. Multiple Intelligence Theory and Foreign Language Learning: A Brain-based Perspective. International Journal of English Studies, 2004, $1^{\text {st }}$ issue, vol. 4, pp: 119-136

[21] A.K. Pujari. Data Mining Techniques. Universities Press, 2001, pp-288.

[22] D. Unay, B. Gosselin, O. Kleynen, V. Leemans, M.F. Destain and O. Debeir. Automatic Grading of Bi-colored Apples by Multispectral Machine Vision, Computers and Electronics in Agriculture, 2011, $1^{\text {st }}$ issue, vol. 75, pp: 204-212.

[23] S. Piao, P. Ciais, Y. Huang, Z. Shen, S. Peng, J. Li, L. Zhou, H. Liu, Y. Ma, Y. Ding, P. Friedlingstein, C. Liu, K. Tan, Y. Yu, T. Zhang and J. Fang. The Impacts of Climate Change on Water Resources and Agriculture in China, Nature, 2010, vol. 467, pp: 43-51.

[24] L. Ding, J. Meng and Z. Yang. An Early Warning System of Pork Price in China Based on Decision Tree, IEEE Conference Proceedings, International Conference on EProduct E-Service and E-Entertainment (ICEEE), Henan, China, 2010, pp:1-6.

[25] A.K. Braimoh, L. Vlek Paul and Stein Alfred. Land Evaluation for Maize Based on Fuzzy Set and Interpolation, Environmental Management, 2004, $2^{\text {nd }}$ issue, vol. 33, pp: 226-238.

[26] M. Smith. Neural Networks for Statistical Modeling. Van Nostrand Reinhold, New York, 1993.

[27] M. Cottrell, B. Girard, Y. Girard, M. Mangeas and C. Muller. Neural modeling for time series: a statistical stepwise method for weight elimination. IEEE Transactions on Neural Networks, 1995, $6^{\text {th }}$ edition, vol. 6 , pp: $1355-1364$

[28] R. Bhagawati, K. Bhagawati, A.K.K. Singh, R. Nongthombam, R. Sarmah and G. Bhagawati. Artificial Neural Network Assisted Weather Based Plant Disease Forecasting System. International Journal on Recent and Innovation Trends in Computing and Communication, 2015, $6^{\text {th }}$ edition, vol. 3, pp: 4168-4173.

[29] C.C. Yang, S.O. Prasher, J.A. Landry, H.S. Ramaswamy and DiTommaso. Application of artificial neural networks in image recognition and classification of crop and weeds. Can. Agric. Eng., 2000, vol. 42, pp: 147-152.

[30] K. Nakano. Application of neural networks to the color grading of apples. Computers and Electronics in Agriculture, 1997, vol. 18, pp: 105-116.

[31] D. Wang, F.E. Dowell and R.E. Lacey. Single wheat kernel color classification using neural networks. Trans. ASAE, 1999, $1^{\text {st }}$ issue, vol.42, pp: 233-240.

[32] W. Hutchinson. Deception in the Cyber-World. In: M. Lehto and P. Neittaanmaki (eds.). Cyber Security: Analytics, Technology and Automation, Vol-78, Springer International Publishing, Switzerland, 2015.

[33] P. Forbes. Dazzled and deceived: mimicry and camouflage. Yale University Press, New Haven Gibson W (1984) Neuromancer. Harper Collins, London, 2009.

[34] H. Hokkanen. Trap cropping in pest management. Annual Review of Entomology, 1991, vol. 36, pp: 119-138.

[35] R.W. Mankin. Applications of acoustics in insect pest management. $C A B$ Review, 2012, $1^{\text {st }}$ issue, vol. 7. www.cabi.org/cabreviews

[36] L.P. Pedigo. Entomology and Pest Management (2nd
Edition). Prentice-Hall, New Jersey, USA, 1996.

[37] J.W. Jones, G.Y. Tsuji, G. Hoogenboom, L.A. Hunt, P.K. Thornton, P.W. Wilkens, D.T. Imamura, W.T. Bowen and U. Singh. "Decision support system for agrotechnology transfer: DSSAT v3". In: G.Y. Tsuji, G. Hoogenboom and P.K. Thornton (eds), "Understanding options for agricultural production". Kluwer Academic Publishers, Dordrecht, 1998, pp 157-177.

[38] C.O. Stockle, S.A. Martin and G.S. Campbell. "CropSyst, a cropping systems model: water/nitrogen budgets and crop yield". Agricultural Systems, 1994, $3^{\text {rd }}$ issue, vol. 46, pp: 335-359

[39] R.L. McCown, G.L. Hammer, J.N.G. Hargreaves, D.P. Holzworth and D.M. Freebrain. APSIM: A novel software system for model development, model testing and simulation in agricultural systems research. Agricultural Systems, 1996, vol.50, pp: 255-271

[40] H.R. Gautam, I.M. Sharma and R.A. Kumar. Climate change is affecting apple cultivation in Himachal Pradesh. Current Science, 2014, $4^{\text {th }}$ issue, vol. 106, pp: 498-499.

\section{Authors’ Profiles}

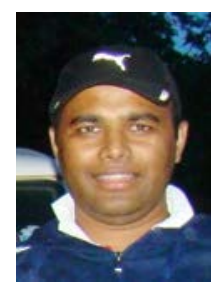

Mr. Kaushik Bhagawati is Research Associate working under National Innovation on Climate Resilient Agriculture project at ICAR Research Complex for NEH Region, Arunachal Pradesh Centre, Basar, India. He is specialized in Computer Application in Agriculture and Agricultural Statistics. His major research interest is on forecasting model based on Artificial Neural Network and SVM. He is the author of around 15 research papers, 5 books and many research articles.

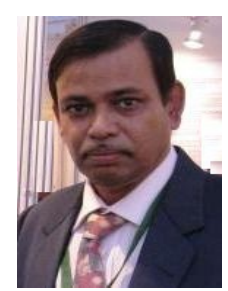

Dr. Rupankar Bhagawati is Joint Director of ICAR Research Complex for NEH Region, Arunachal Pradesh Centre, Basar, India. He is an eminent scientist of Plant Pathology and has done lot of works on Rice Disease. He has contributed lot towards sustainable development of hill farming especially in the Eastern Himalayan region of India. His major research area includes improvement of shifting cultivation, climate resilient agriculture, plant disease forecasting, temperate horticulture etc. He is the author of around 40 research papers and above 100 research articles. He is recipient of Bursary Award from Royal Society of Edinburgh, UK for ICPP98.

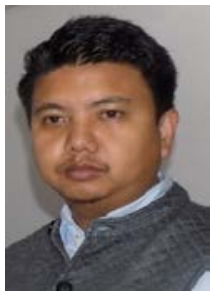

Dr. Doni Jini is Scientist (Veterinary Extension) at ICAR Research Complex for NEH Region, Arunachal Pradesh Centre, Basar, India. His major research interest is on study of livestock/poultry behavior under changing climate scenario. $\mathrm{He}$ has contributed lot towards veterinary development under hill ecosystem. He is author of several internationally recognized research papers and research articles. 